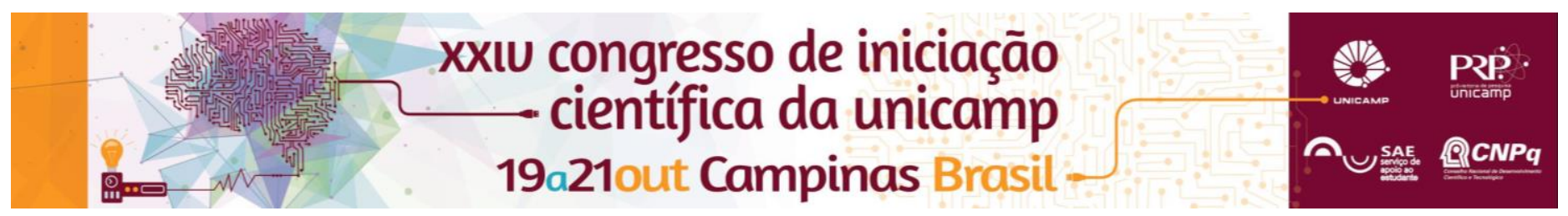

\title{
Um estudo sobre o mercado de tabaco no Brasil: o lado da oferta
}

\section{Rodrigo Mancini, Marcelo Justus.}

\section{Resumo}

Há um claro conflito entre o lado econômico e social do mercado de tabaco. Logo, analisá-lo minuciosamente é justificável. O objetivo principal do estudo proposto é analisar o lado da oferta do mercado brasileiro de tabaco nos anos recentes. Em termos específicos, será construída uma base de dados de séries temporais com o intuito de realizar previsões da produção, importações e exportações de tabaco do Brasil até 2020.

\section{Palavras-chave:}

Tabagismo, Séries temporais, Econometria.

\section{Introdução}

O tabagismo é definido como o consumo sistemático de produtos feitos com folha de tabaco que, em geral, causam dependência química e psicológica devido à nicotina. O tabaco é a droga mais utilizada e disseminada no mundo. Assim, é fundamental dimensionar o tamanho do mercado tanto do lado da demanda como da oferta.

A Organização Mundial da Saúde considera o tabagismo como a principal causa de morte evitável no mundo. Apesar disso, esta atividade econômica ainda é uma das principais para inúmeros pequenos agricultores no Sul do Brasil. O objetivo principal do estudo proposto é analisar - lado da oferta do mercado brasileiro de tabaco nos anos recentes. Os objetivos específicos são:

a) Montar uma base de dados de séries temporais contendo a produção, importações e exportações de tabaco do Brasil;

b) Realizar previsões da produção, importações e exportações de tabaco brasileiro até 2020.

\section{Resultados e Discussão}

Os modelos referentes à importação e exportação utilizam como base de dados o Sistema Integrado de Comércio Exterior (SISCOMEX), que administra o comércio exterior brasileiro. São dados mensais, de 1997 até 2015. No que diz respeito ao modelo da produção, foram utilizados dados obtidos pelo Sinditabaco. Os dados são referentes à produção total de tabaco no Sul do país, que concentra mais de $95 \%$ da produção.

O software utilizado nas análises e resultados apresentados nesse trabalho foi o "R" e todas as análises serão baseadas num intervalo de confiança de $95 \%$. Os modelos de previsão serão construídos com base na metodologia de Box-Jenkins para modelos autorregressivos de média móvel (ARMA).

Figura 1. Previsão da exportação de tabaco

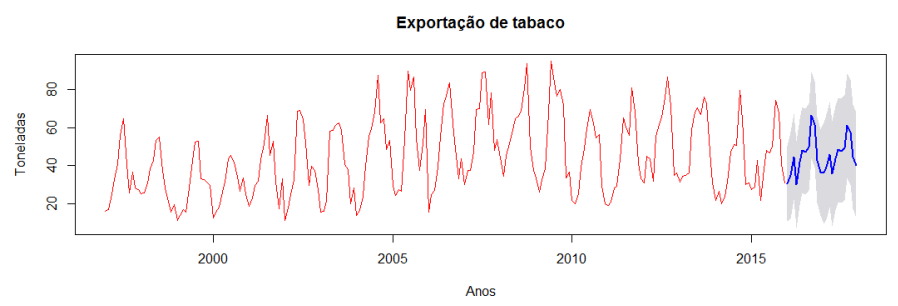

Figura 2. Previsão da importação de tabaco

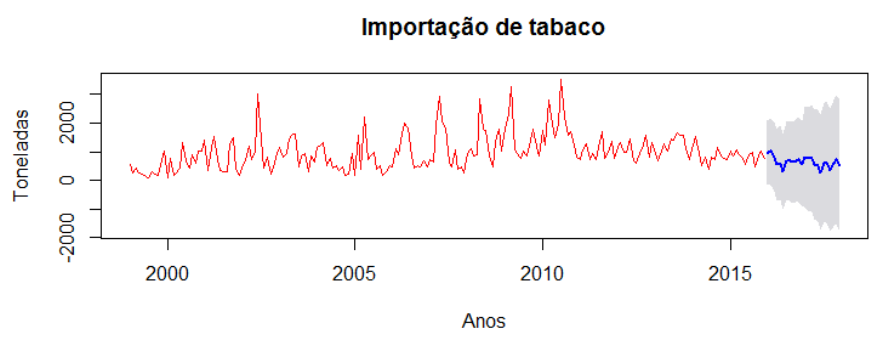

É importante salientar que a medida que a previsão aumenta, maior será o intervalo de confiança. Portanto, quanto mais se distancia dos dados iniciais, menos robusta se torna a previsão.

\section{Conclusões}

Após a análise dos resultados, concluiu-se que, assim como esperado, a previsão é de que a produção de modo geral diminua. Ambos os modelos - de exportação e importação - também indicaram uma tendência à queda.

Deste modo, após a elaboração dos modelos e análise dos resultados, é necessário realizar uma discussão acerca dos novos dados levantados. Algumas hipóteses para justificar o resultado obtido seriam o cenário internacional desfavorável (Convenção-Quadro), a criação da lei do preço mínimo, a elevada tributação que incide sobre o fumo e o comércio ilegal de tabaco e cigarro.

\section{Agradecimentos}

Instituto de Economia, Universidade Estadual de Campinas.

Buainain, A. M., L. L. CALIXTO, e H. M. DE SOUZA FILHO (2009). Organização e funcionamento do mercado de tabaco no sul do Brasil: agricultura, instituições e desenvolvimento sustentável. Unicamp.

Barry, M. (1991). The influence of the US tobacco industry on the health, economy, and environment of developing countries. The New England journal of medicine 324(13), 917-920. 